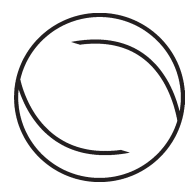

\title{
Standardization Cycles: A Process Perspective on the Formation and Diffusion of Transnational Standards
}

Organization Studies $33(5-6) 737-762$

(C) The Author(s) 2012

Reprints and permission: sagepub.co.uk/journalsPermissions.nav DOI: $10.1177 / 0170840612443626$

www.egosnet.org/os

(SAGE

\author{
Sebastian Botzem \\ Social Science Research Center, Berlin, Germany
}

\section{Leonhard Dobusch}

Freie Universität Berlin, Department of Management, Germany

\begin{abstract}
Standards are receiving increasing attention, especially at the transnational level where standardization aims at coherence and social ordering beyond the nation-state. However, many attempts to bring about uniformity via formalized standards fail. To understand better how such rules successfully span national and organizational boundaries over time, we compare two cases of standardization in international business. Both Windows desktop software and International Accounting Standards demonstrate the need for a process perspective to understand and explain social ordering through standards. Long-lasting standardization processes require conceptualizing how different sequences of transnational standardization relate to each other. We find that at the core of such recursive cycles is the interplay of input and output legitimacy.
\end{abstract}

\section{Keywords}

input legitimacy, output legitimacy, standard diffusion, standard formation, standardization process

\section{Introduction}

Standards are receiving increasing attention, particularly beyond the nation-state. Organizations use standards to ease transactions and to structure their internal affairs as well as the world around them. Standards' ability to structure interorganizational relations makes them particularly suitable to study rule-making at the transnational level, both empirically and conceptually. Their capacity to enhance coordination makes standards particularly apt to fill the regulatory void detected beyond the national sphere (see Braithwaite \& Drahos, 2000; Djelic \& Sahlin-Andersson, 2006; Mattli, 2003). Recent accounts of standardization literature discuss an interesting discrepancy: for one, a ubiquity of standards is detected, which penetrates many aspects of individual and organizational

\section{Corresponding author:}

Sebastian Botzem, Social Science Research Center, Berlin, Germany

Email: botzem@wzb.eu 
life. Secondly, standards are contested and volatile, and only become authoritative rules under certain conditions that need further specification: 'Standards transform by coordinating disparate elements, but the outcomes that standards achieve depend on the specific standards and the circumstances under which they are made to work' (Timmermans \& Epstein, 2010, p. 84).

Despite recent interest in standardization, standards are less of a novelty than might appear at first sight. They have been an object of analysis for some considerable time and in a number of disciplines: In technology studies and economics, the coordination and network effects of standards are widely discussed (David \& Greenstein, 1990; Farrell \& Saloner, 1986; Genschel, 1997; Katz \& Shapiro, 1985; Schmidt \& Werle, 1998; Weitzel et al., 2006; Werle \& Iversen, 2006). Sociological approaches take an interest in the political and normative dimensions related to standard setting, including various modes of participation (Ahrne et al., 2007; Boli \& Thomas, 1999; Brunsson \& Jacobsson, 2000a; Djelic \& Sahlin-Andersson, 2006; Fransen \& Kolk, 2007; Tamm Hallström \& Boström, 2010). Astonishingly, the various streams of literature make little reference to one another, missing opportunities for multi-disciplinary debate and learning. This leads us to take a fresh look at the strengths of different perspectives to identify conditions of achieving transnational order in the absence of public authority. We suggest a holistic approach to standardization, defining it as a process in which the formation of standards and their subsequent diffusion are shaped by actors and closely interrelated. Such a perspective epitomizes the role of actors in building and sustaining social order outside of organizations in general, and the importance of specific actor constellations, resources, and circumstances in particular. And it underscores the need to be perceived as being legitimate, that is, as a proper and appropriate standard setter (Suchman, 1995).

Our process perspective goes beyond merely claiming the dynamic character of standardization: We argue that the various phases of standardization not only follow upon each other, but are mutually related and potentially reinforcing. Our core argument is that the genesis and proliferation of standards are interlinked, making up a recursive cycle of transnational standardization. In this article, we argue that effective standardization - the setting, diffusing, and implementing of rules depends on the reciprocal linkage of the formation and diffusion of standards. Feedback between the two phases emphasizes the importance of distinguishing between different types of legitimacy most importantly, input and output legitimacy - to understand and explain transnational standardization (Mayntz, 2010; Quack, 2010; Tamm Hallström \& Boström, 2010). Such a legitimacy-centred perspective is suitable to analytically integrate functionalist understandings, which focus primarily on successful standardization based on effectiveness (i.e. the output of standardization, e.g. Abbott \& Snidal, 2001; Genschel, 1997) and social understandings, which emphasize the political nature of standardization processes (i.e. the input of standardization, e.g. Boli \& Thomas, 1999; Fransen \& Kolk, 2007; Mattli, 2003).

The aim of our article is to develop an integrative approach, cutting across disciplinary limitations and overcoming a static and linear understanding of social ordering through standards. Focusing on the transnational level, we amplify standardization research by explaining how the interplay of standard formation and diffusion conditions developments in standard setting and shapes the involvement of different actor groups. Accounting for change over time not only provides insights into how standards proliferate, but allows for the analysis of different modes of standardization. Discussing the emergence of social order enables us to address the logics of standardization per se and prepare common theoretical ground for further research. To that end, we present a conceptual framework derived from an ex-post induction of two prominent cases of design standards (Timmermans \& Epstein, 2010) in the field of international business. The first case is the market for desktop PC operating systems with Microsoft Windows as today's dominant de-facto standard. The second case is International Accounting Standards (IAS), which define rules 
for the preparation of corporate financial reports. Comparing two cases enables us to answer the following questions: How do the formation and diffusion of standards relate to each other? How can such a process perspective on standardization be conceptualized?

To address these questions, the article is structured as follows: the theoretical section summarizes key works of standardization literature to consider the interrelatedness of different phases of standardization. It ends with our own suggestion of a process model of standardization. Subsequently, we reconstruct the two empirical cases with regard to commonalities and differences in the formation and diffusion of standards. The next section analyses the characteristics of both processes of standardization. Lastly, we summarize our findings, addressing insights with regard to the organizational dimensions of transnational standardization.

\section{Theory: Standardizing Standards}

Citing Hemenway's (1975, p. 8) classic one-liner - 'ironically, standards have not been completely standardized' - Weitzel et al. (2006, p. 491) speak of a 'bewildering variety of approaches to defining standards'. The plurality of meanings is heightened by disciplinary fragmentation contrasting economic and sociological perspectives, technological and non-technological approaches, or formal and de-facto standards. These strands make very little reference to each other, neglecting many benefits of cross-fertilization (see Mattli \& Büthe, 2005; Schmidt \& Werle, 1998, for notable exceptions). Efforts to bridge these gaps are to be found in research on transnational governance and regulation which emphasizes the role of standards in bringing about social order beyond the nation-state (Boli \& Thomas, 1999; Brunsson \& Jacobson, 2000a; Kerwer, 2005; Mattli, 2003). More generally, standards are prescriptions on how to behave. For our purpose, we define them as detailed rules structuring interaction: 'By rules we mean explicit, almost always written, statements that prescribe how certain actors must behave in certain situations' (Ahrne \& Brunsson, 2006, p. 82).

In the transnational realm, standards play a particular role as organizational elements outside formal organizations (Ahrne \& Brunsson, 2006, p. 82). Together with other norms such as bestpractice rules or guidelines, standards are commonly considered to embody the expertise of a respective field in a relevant way. This aspect is accentuated by the importance of non-state actors in standard development, such as private standard-setting bodies, corporations or industry consortia. However, standard formation is not detached from public authority, which plays an important role in legitimizing the genesis of standards (Botzem \& Hofmann, 2010; Rose \& Miller, 1992). To shed light on the more specific characteristics of transnational standards, we start with a discussion of commonalities and differences between various concepts of standardization. We argue that they share two basic assumptions which are important to grasp the procedural nature of standardization: first, transnational standards fulfil a coordinating function and, second, their emergence is orchestrated by private actors.

For one thing, understanding standards as a means to coordinate action points to the inherently dual nature of standards as enabling and - simultaneously - constraining social interaction. By definition, standardization implies striving for a social order which 'requires the submission of diverse actors' (Timmermans \& Epstein, 2010, p. 84). Standards make coordination possible by limiting individual leeway. Consequently, the literature on standard formation deals with issues such as stakeholder participation (Tamm Hallström \& Boström, 2010; Werle \& Iversen, 2006) and highlights the importance of negotiating rules (Becker et al., 2003; Schmidt \& Werle, 1993). In institutional economics, the coordinative function of such private rules is widely discussed and the prime benefits of standards are attributed to lower transaction costs, which translate into an overall increase in welfare (e.g. Abbott \& Snidal, 2001; North, 1990). 
For another thing, standards are particularly effective as a means of transnational regulation where the social order is just emerging (Djelic \& Quack, 2003; Djelic \& Sahlin-Andersson, 2006) or existing orders require adaptation, extension or correction (e.g. Dobusch \& Quack, 2010). Their advantage is the provision of sector-specific coordination solutions in areas in which public rulesetting has not been sufficient or was unsuccessful. Standards' primary objective is to encourage actors to behave in a similar fashion, producing uniformity across time and space (Brunsson \& Jacobsson, 2000b, p. 14). Some authors see standards as optional and as alternatives to public institutions (Cutler et al., 1999), conceptualizing them as a functional equivalent to international regimes (cf. Pattberg, 2005). At the transnational level, standards are sometimes considered to be 'voluntary best-practice rules' (Kerwer, 2005, p. 611). However, a closer look at how and under what conditions standards are followed reveals the importance of third parties in disseminating standards. While in the abstract, standards are voluntary rules, in practice, third parties can play a fundamental role in pushing adopters to follow a standard, making them virtually obligatory for the actors depending on them. The degree of voluntariness might be reduced until the adopter 'will have no choice but to follow certain standards' (Brunsson \& Jacobsson, 2000c, p. 134).

A closer look at the diffusion of standards reveals the quasi binding nature of many established rules, even when they do not formally enjoy authorization by public actors. The positive relationship between the diffusion and binding quality of standards has been a core argument in research on technological standardization. Both network effects (Besen \& Farrell, 1994; Katz \& Shapiro, 1985; Shapiro \& Varian, 1999) and 'crowd effects' (Timmermans \& Epstein, 2010, p. 79), whereby not following the standard leads to cost (see also Funk \& Methe, 2001; Koski \& Kretschmer, 2005), favour coercion. However, there is a potential trade-off between individual gains and collective, network-wide benefits that is inherent to standardization processes (Weitzel et al., 2006). Similar observations are also made in the realm of social standards, where the diffusion and binding quality of a standard are interrelated, often mediated via legitimacy (see, for example, Bartley, 2007; Delmas, 2002). As we will argue in the later part of this paper, benefits generated through the diffusion of standards feed back into the cycle of standard formation, diffusion, adoption, and reproduction. In addition to material and power resources and authority, legitimacy plays a key role in linking different phases of standardization in most strands of standardization research.

\section{I Linking functional and social conceptualizations: Legitimacy}

Much of the existing literature can be grouped into one of two camps of standardization literature: functional conceptualizations are said to underline the coordinative effects of standards, while sociological understandings allegedly point to their genesis and normativity. Feng (2003, p. 92) distinguishes between functionalist views (e.g. Cargill, 1989; Liebowitz \& Margolis, 2001) that interpret standard setting mainly as solving an 'engineering problem' to reduce transaction costs, on the one hand, and constructivist views (e.g. Egyedi, 1996; Schmidt \& Werle, 1993, 1998) that conceptualize standardization as 'social negotiations', on the other hand. Commonly, functional perspectives consider standards to be specifications guiding but also enabling action.

Functionalist approaches that emphasize formal modelling (e.g. Weitzel et al., 2006) or game theory (e.g. Genschel, 1997) largely neglect the cultural and organizational aspects of standardization (cf. Storz, 2007), making it difficult for constructivist approaches to relate to the coordination arguments of that tradition. Despite acknowledging the importance of standard diffusion in general (Besen \& Farrell, 1994; Farrell \& Saloner, 1987), functional approaches are weak on explaining empirical variance between fields with similar coordination benefits and actor constellations. One 
reason for this is a lack of attentiveness to the power differentials inherent in standards and enforced by them as a form of governing beyond the state (see Rose \& Miller, 1992).

By pointing to the generation of uniformity, sociological conceptualizations of standardization emphasize the relevance of a sequential understanding of rule-setting (Brunsson \& Jacobsson, 2000a; Fransen \& Kolk, 2007; Seidl, 2007; Tamm Hallström \& Boström, 2010). Ahrne and Brunsson (2006, p. 83) stress the fact that while 'organizations often evoke protests and complaints, this is rarely the case for standards'. Such a nuanced understanding of dispersed agency in collective rulemaking - in particular at the transnational level - points to the importance of feedback between privately generated standards and their subsequent diffusion. The effectiveness of standards as a form of governing (Rose \& Miller, 1992) depends on standardization being responsive and standards being amendable. In practice, the likeliness of a successful diffusion of standards is influenced by the possibility to revise standards over time. Our empirical cases will show that the degree of voluntariness of standards can only be assessed if full standardization cycles are considered. The interdependence of standard formation and diffusion, combined with responsive action by focal standard-setting organizations, reinforces the supposition that initially voluntary standards become de-facto binding rules. In this context, the strategic construction of legitimacy is one vital element to overcome weaknesses in the enforcement capacities of transnational standard setters (Tamm Hallström \& Boström, 2010, p. 23) and makes them a relevant object of interest for empirical research. These organizations seek legitimacy for various reasons, one of them being the pursuit of both continuity and credibility (Suchman, 1995, p. 574). Given the regulatory void at the transnational level, being legitimate is important in standardization processes as it signals 'the rightfulness and appropriateness of authority' in bringing about political and social order (Quack, 2010, p. 8). Transnational standards therefore depend on the perception that standard setting and the output of these processes are considered 'desirable, proper, or appropriate' (Suchman, 1995, p. 574).

To balance the aspects stressed in functional and sociological approaches in a fruitful way, we suggest putting the concept of legitimacy at the centre. As mentioned above, most of the literature on standardization (at least implicitly) refers to different sources of legitimacy, regularly referred to as 'input' and 'output' legitimacy (cf. Lövbrand et al., 2009; Quack, 2010; Scharpf, 1999). ${ }^{1}$ Referring to Weber's category of legality based on consensus ('Vereinbarung'), Mayntz (2010, p. 10) defines input legitimacy 'as given if those who are subject to a regulation participate in devising it' (see also Willke, 2007). In her understanding, this also incorporates procedural legitimacy (Quack, 2010; Tamm Hallström \& Boström, 2010). In turn, Mayntz (2010, p. 10) defines output legitimacy as 'legitimacy based on substantively rational decision results'. The capacity to solve collective problems or to meet the expectations of standard adopters generates output legitimacy, which, in a narrow sense, could be understood as a functional imperative of minimizing transaction costs.

Input legitimacy originates from stakeholder involvement in the process of standard formation. Stakeholders are usually acting as organizations, but may also include individuals, many of whom are considered to be experts in a particular field. In this context, standard setters may generate input legitimacy by strategically engaging third parties (see Tamm Hallström, 2004, pp. 152ff., for 'reference organizations' and Tamm Hallström \& Boström, 2010, pp. 145ff., for 'high profile actors'). The special position of these third parties usually derives from specialized expertise and moral or political authority. Output legitimacy in turn results from the effectiveness and coordinative capacity of a standard and is therefore predominantly related to its diffusion. In addition to coordination effects brought about by standards, subordinates also need to believe in the legitimacy attached to regulatory output (Quack, 2010, p. 8). Again, third parties play an important role in fostering diffusion by endorsing or even demanding certain standards from their interaction partners, such as multinational 
corporations or member states in the case of the European Union. The role of legitimacy is fundamental, because it is not only needed to achieve 'day-to-day compliance, but long-term stability' (Mayntz, 2010 , p. 15). However, legitimacy is not persistent per se, and converting legitimacy from episodic to continual forms becomes a clear objective (Suchman, 1995, p. 595). Tamm Hallström and Boström (2010, p. 160) remind us that legitimacy is not a stable condition but 'must be repeatedly created, recreated, and conquered'. In our view, this can only be captured by a process perspective which accounts for the interrelatedness of standard formation and standard diffusion. A dynamic understanding reveals how, in each phase, different forms of legitimacy are created and modified. The analysis of legitimation strategies (cf. Suchman, 1995; Tamm Hallström \& Boström, 2010) emphasizes the conditions of participation and the role of actor constellations in standardization.

After standards have become de-facto rules, they may still prevail when their input legitimacy is questioned. While the relationship of input and output legitimacy should not be conceptualized as one of juxtaposition, there are indications of a trade-off between the different modes. As Tamm Hallström and Boström (2010, p. 161) show, particularly in multi-stakeholder arrangements, there is potential for conflict between input legitimacy and output legitimacy, pointing to the importance of actor constellations, the availability of resources, and development over time. This also confirms the recursiveness of standardization, in particular the recurrent adaptation or even re-formulation of standards (Lampland \& Star, 2009). A dynamic perspective with regard to both standard setting and dissemination allows us to detect alterations in the power relations of actors engaged in standardization. Consequently, standardization should be understood as an organized and potentially infinite process of sequences of standard formation and diffusion.

\subsection{A process perspective on standardization}

A process perspective allows for a comprehensive analysis of standards' trajectories, standardization practices and agents of change. The analytical distinction between different phases of standardization takes up a commonly detected multi-stage understanding of standard setting (cf. Brunsson \& Jacobsson, 2000a). Often, however, stage models suggest a linear development of standards (e.g. Timmermans \& Epstein, 2010, p. 74). Drawing on discussions of transnational law-making (Halliday \& Carruthers, 2007; Quack, 2007), we argue that standardization instead occurs in recursive cycles. In such cycles, different actors may be involved in different phases, or the same actors may contribute to several phases of standardization (Quack, 2007, p. 652). In this section, we will present our cyclical process model of standardization, which considers organizational change and institutionbuilding as contextualized processes (cf. Pettigrew, 1990). Together with the analytical distinction between rule making and diffusion, a cyclical perspective allows us to unveil each dimension and to tease out the constitutive nature of different forms of legitimacy in transnational standardization. As a first dimension, we distinguish between inclusive and exclusive standard formation. Then, we discuss standard diffusion as the second dimension of standardization cycles. In a third step, we position four ideal types of standards in a field defined by these two dimensions.

Exclusive formation is characteristic of proprietary market standards developed unilaterally by a single organization - e.g. today's Microsoft Windows desktop software (Campbell-Kelly, 2001). Exclusive formation can also be found in cases of non-proprietary standards such as the QWERTY keyboard, which was developed - but not owned - by a single corporation (cf. David, 1985). In these cases, a sole actor, usually a for-profit organization, develops a standard and proposes its adoption. Whether these exclusively developed rules eventually become accepted standards, however, depends on additional aspects during the diffusion phase, as we will show in the empirical section of the paper. 
In contrast, inclusive formation is a relatively open, collaborative procedure, usually characterized by negotiations among a number of interested parties, creating input legitimacy ('multi-stakeholder standardization', see Fransen \& Kolk, 2007; Tamm Hallström \& Boström, 2010). Discussion and bargaining typically play an important role, but discourse tends to vary according to specific issue fields: many instances of technical standardization, for example, follow such a mode in which expert committees play a key role as a forum for negotiations (see, for example, development of technologies for Digital Rights Management, DRM, in Becker et al., 2003; Rosenblatt et al., 2002). Framing standardization decisions on the basis of expertise, as is common in technological standardization, nevertheless remains a political affair even though discourse might be less openly politicized than in cases of social and environmental standards (cf. Mattli, 2003; Schmidt \& Werle, 1998). Examples of such inclusive standards are, for instance, many of ISO's technical standards (Mattli, 2003; Tamm Hallström, 2004) or international accounting standards (Botzem \& Quack, 2006; Perry \& Nölke, 2005; Tamm Hallström, 2004). Whether inclusiveness eventually fosters (e.g. through combining complementary capabilities, see Keil, 2002) or hinders (e.g. by long and complicated conflict resolution procedures, see Genschel, 1997) diffusion is an empirical question (see also Schmidt \& Werle, 1998). In every case, however, the mode of standard setting has an impact on the diffusion of standards.

As outlined above, standard diffusion is the second dimension of standardization. The dissemination of rules is a prerequisite to a lasting standardization regime, since high adoption contributes to output legitimacy. The relationship between standard diffusion and output legitimacy is recursive due to network or crowd effects (Besen \& Farrell, 1994; Timmermans \& Epstein, 2010, p. 79). High adoption rates increase the coordination power of standards, which lies at the heart of output legitimacy. This in turn increases the likelihood of further adoption. Within the overall cycle of standardization, the relation between diffusion and output legitimacy constitutes an additional feedback loop.

However, as the case of accounting standards shows, a considerable time lag between the formation and the diffusion of standards is possible. After standards have become locally adapted, reformulated and interpreted, they re-enter the (re-)formation phase of standardization whenever rules are revised and modified, potentially leading to a redistribution of standard-setting power among the actors involved. In addition, the anticipation of such diffusion dynamics during the formative period might significantly influence actors' strategies, for example when aiming for 'path creation' (e.g. Garud \& Karnøe, 2003).

Such a recursive understanding of standardization allows us to reveal how, over time, output legitimacy, often aided by third-party enforcement, affects standard formation. Output legitimacy might complement, but also has the potential to replace input legitimacy. In the latter case, successful dissemination might lead to a decrease in openness and participation indicating a possible trade-off between these two forms of legitimacy. In empirical terms, such dynamics are likely to be connected to changing actor constellations and organizational transformations. At this point, however, our argument is conceptual and we claim that standard formation and diffusion are recursively related, with input and output legitimacy being key explanatory factors for that relation.

Figure 1 exemplifies our main argument: standard formation and diffusion are reciprocally linked, drawing on different sources of legitimacy. This relationship is reciprocal insofar as the outcome of a particular mode of formation affects the diffusion of standards, which has repercussions on future procedures of standard (re-)formation.

The analytical distinction between standard formation and diffusion not only allows conceptualizing recursivity but also deriving four different types of standards according to these dimensions (see 


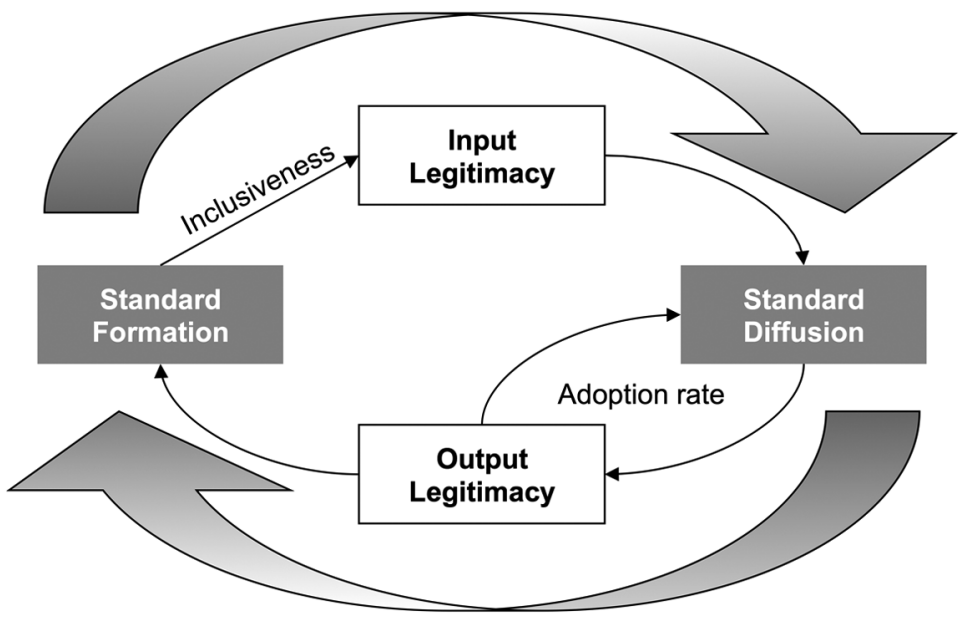

Figure I. Recursive cycle of transnational standardization Source: Own Composition.

Figure 2). Competing standards (1) are found when two or more incompatible standards are exclusively set and rival for dominance. In the case of de-facto standards (2), one unilaterally formed standard is widely adopted. Multiplicity of standards without cut-throat competition - for example, in the case of different national standards - represents coexisting standards (3). Widely adopted standards stemming from inclusive standard setting are examples of collective standards (4).

To trace standardization over time, we suggest looking at transitions of standards from one such ideal type to another, tracking how standards 'travel' over time. A frequent route is competition between standards, which might result in a single de-facto standard as shown in the Windows case below. A contested standard, however, might also be converted into a collective standard. That happened when the International Standardization Organization (ISO) officially adopted the QWERTY keyboard standard. Moreover, new actors might try to re-introduce competition on markets with established de-facto standards (e.g. the nascent free/open source software movement in the Microsoft Windows case). Finally, the inclusive but parallel development of coexisting standards can be the first stage of negotiating comprehensive collective standards (e.g. the DIN A-4 paper format). ${ }^{2}$ However, the competition of standards might also result in standard wars, as happened in the case of VHS vs. Beta video formats (Cusumano et al., 1992). In the following section, we turn to two prominent cases of transnational standardization: the Microsoft Windows case as a technological de-facto standard and the International Accounting Standards (IAS) as a case of a negotiated regulatory standard, and their developments over time.

\section{Contrasting Cases: PC Operating Systems and International Accounting Standards}

\section{I Method: Case selection and data collection}

Microsoft Windows and International Accounting Standards have so far been discussed as icons of technological and sociological standards respectively. Striving for analytical generalization, we deliberately selected two exemplary cases, each dominating their field. Our case selection is motivated by 


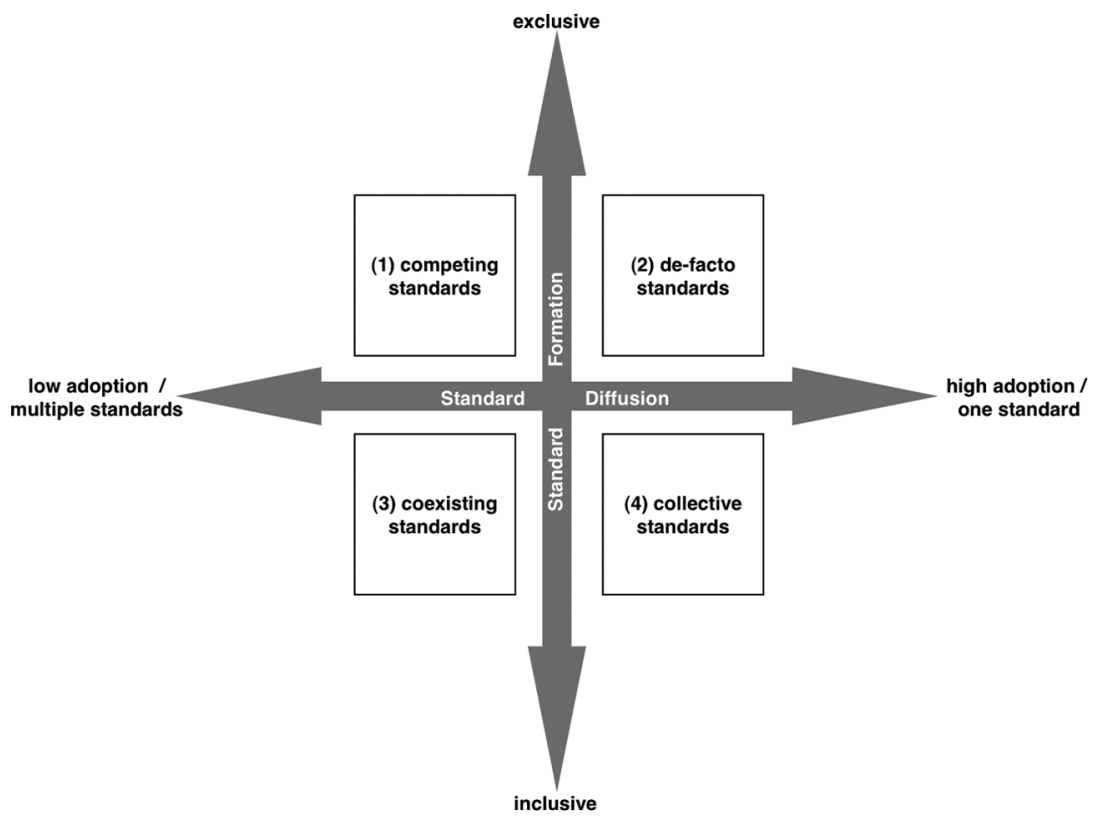

Figure 2. Two dimensions of standardization: formation and diffusion

Source: Own composition.

similarities and differences between the cases that allow us to investigate the interrelatedness of standard formation and diffusion at the transnational level. Desktop software and accounting standards share some important properties: both are formalized standards coordinating and facilitating the flow of information and capital in the ambit of international business. Their development has been characterized by setbacks, contestation and modification. Desktop software has been predominantly driven by corporate actors, while in accounting professional organizations and service providers have played a key role. Both cases are private initiatives in the sense that (quasi-)governmental standard-setting organizations such as the International Organization for Standardization (ISO) or CEN (Comité Européen de Normalisation) do not play an important role in standard setting. Instead, two private organizations dominate standardization: the Microsoft Corporation and the International Accounting Standards Board (IASB), respectively. While the former is a profit-oriented corporation which offers a wide array of services, many of them in some way connected to the proprietary Windows standard, the latter is a standard-setting organization set up as a not-for-profit foundation.

Regarding the nature of the standards, both resemble the same type of rule. Windows desktop software and International Accounting Standards are design standards. 'Design standards set structural specifications: They define the properties and features of tools and products. Such standards are explicit and more or less detailed specifications of individual components of social and/or technical systems, ensuring their uniformity and their mutual compatibility' (Timmermans \& Epstein, 2010, p. 72). The focus of Windows is standardizing the properties of information technology systems, while IAS seek to establish and ensure the compatibility of corporate financial reports, which we interpret as socially constructed information systems.

Within the scope of these commonalities, our cases exhibit some differences with respect to the relation between standard formation and diffusion that makes them particularly promising cases for studying the cyclical characteristics of standardization. With regard to the initial formation of 
Table I. Case selection characteristics

\begin{tabular}{|c|c|c|}
\hline Case selection characteristics & PC operating systems & Accounting Standards \\
\hline Ambit & \multicolumn{2}{|c|}{ International business and trade } \\
\hline \multirow[t]{2}{*}{ Standard type } & \multicolumn{2}{|c|}{ Design standard } \\
\hline & technological ('de-facto') & negotiated \\
\hline \multirow[t]{2}{*}{ Standard setter } & \multicolumn{2}{|c|}{ Private organization } \\
\hline & for-profit company & non-profit organization \\
\hline Standard diffusion & $\begin{array}{l}\text { Initially contested, today } \\
\text { dominant }\end{array}$ & $\begin{array}{l}\text { Initially restrained, } \\
\text { today dominant }\end{array}$ \\
\hline
\end{tabular}

Source: Own composition.

standards, Windows clearly belongs to the category of exclusively developed standards. For roughly two decades, with only a short initial period of cooperation with IBM and other corporate actors, Microsoft developed Windows unilaterally. The proprietary nature of Microsoft's desktop operating system was and still is the core of a successful business model, which has expanded into a variety of neighbouring fields such as application and server software or the gaming industry (e.g. 'Xbox'). In contrast, IAS started as an inclusive project of a federation of various national associations. Its early standards were a selection of different (even conflicting) national rules and prescriptions that were only marginally edited, interpreted and, at a later stage, revised. Differences between the cases are also reflected in the diffusion of the standards. While Windows had an early start and managed to out-compete rival desktop publishers, for a long time IAS's diffusion was an uncertain affair that relied on careful coalition building between the focal standard-setters and third parties, public and private alike. With regard to the combination of standard formation and diffusion, Windows and IAS started as distinct cases. Our ex-post reconstruction in the following sections, however, shows that today, differences between the two have been substantially reduced. Table 1 gives an overview of the two cases representing globally diffused design standards, which differ with regard to the following criteria: Windows is an example of a technological de-facto standard that became dominant via market competition, while IAS is a privately negotiated standard which has become dominant due to public endorsement.

Both cases have been covered widely in the literature, facilitating their analysis based on existing research. Our reconstruction of the two standardization processes resembles historical approaches relying mainly on secondary sources (see, for example, Campbell-Kelly, 2001, 2003) and is complemented by interviews with field actors. In an approach best described as a qualitative meta-case study (see also Arts, 2003; Layder, 1998), we extract empirical data from studies with a variety of theoretical backgrounds, and rely on information given in documents and expert interviews. The rationale for conducting the latter was to corroborate and empirically ground our understanding of the case descriptions presented in the literature.

We chose different approaches to selecting interview partners in order to account for empirical differences. Since Microsoft Windows emerged in the desktop software market as the sole and proprietary setter of a de-facto standard, we attended practitioners' conferences and spoke with a total of 26 IT managers of private and public sector organizations who were involved in software adoption decisions. These interviews helped to identify drivers behind and barriers to (re-)adopting Microsoft Windows or alternative desktop operating systems. In the case of International Accounting Standards we conducted interviews with a total of seven individuals involved in standard setting at the national and international levels. Amongst them were high profile standard setters 
Table 2. Interview data

\begin{tabular}{lll}
\hline Case & PC operating systems & Accounting standards \\
\hline Interview partners & $\begin{array}{l}\text { IT managers involved in } \\
\text { operating system adoption } \\
\text { decisions in private and public } \\
\text { sector organizations } \\
\text { Practitioners' conferences }\end{array}$ & $\begin{array}{l}\text { High profile national and } \\
\text { international standard setters }\end{array}$ \\
Interview setting & $\begin{array}{l}\text { What are drivers behind and/ } \\
\text { or barriers to (re-) adopting } \\
\text { Microsoft Windows or any } \\
\text { alternative desktop operating } \\
\text { system? }\end{array}$ & $\begin{array}{l}\text { Interviewees' work } \\
\text { environment }\end{array}$ \\
& $\begin{array}{l}\text { How have rules of } \\
\text { participation and standards' } \\
\text { content been altered over } \\
\text { time? }\end{array}$ \\
Which actors were involved \\
in the formation process and \\
in what form?
\end{tabular}

Source: Own composition.

of the International Accounting Standards Board. Questions asked in this context dealt with issues such as how the rules of participation have been altered over time, how standards have been amended, and what interest groups were involved in the formation process. While we compiled verbatim transcripts of our interviews, which varied in length from 30 minutes to two hours, we abstained from systematically comparing codes applied to those interviews due to the substantial differences between the cases in general and interview partners in particular. Table 2 presents an overview of the interview data collected.

In the following sections we first briefly describe standard formation and diffusion for each of the two cases and then apply our conceptual framework developed above to compare the two standardization processes systematically.

\subsection{From competing to de-facto standards: PC operating systems}

Today, after 15 years of constant market shares way above 90 percent in the desktop segment, analyzing Windows under the heading of 'competing standards' might appear surprising. However, there has been and still is some - albeit different - competition in this field. For the mid-1980s, Campbell-Kelly lists five comparable windowing systems just for IBM-compatible PCs, leaving out desktop-pioneer Apple's MacOS (see Table 3).

In subsequent years Microsoft managed to achieve a monopolistic position in the two most important and closely related segments of the desktop software market, operating and office systems. For Liebowitz and Margolis (2001, p. 235), this was due to Microsoft's product quality: 'Our message is simple: Good products win.' Others (e.g. Campbell-Kelly, 2001; Shapiro \& Varian, 1999) stress the path-dependent nature of this competitive struggle. Numerous 'small events' (Arthur, 1989) - including strategic moves made by Microsoft and its competitors - culminated in the proprietary de-facto standard of Windows and Office that we live with today. An example of such 'small events' is IBM's decision to only license and not buy the Windows-predecessor DOS as an operating system for personal computers, which supplied Microsoft with a large installed 
Table 3. Windowing-systems for IBM-compatible PCs, 1984-1985

\begin{tabular}{|c|c|c|c|c|c|}
\hline Publisher & Product & Price (US\$) & Announced & Released & Notes \\
\hline VisiCorp & VisiOn & 495 & November 1982 & January 1984 & $\begin{array}{l}\text { Price reduced } \\
\text { to US\$ } 95\end{array}$ \\
\hline Digital Research & GEM & 399 & November 1983 & September 1984 & $\begin{array}{l}\text { Price included } \\
\text { concurrent } \\
\text { DOS }\end{array}$ \\
\hline Microsoft & Windows 1.0 & 95 & November 1983 & November 1985 & \\
\hline IBM & TopView & 149 & August 1984 & February 1985 & \\
\hline Quarterdeck & DESQ & 399 & Spring 1983 & May 1984 & \\
\hline
\end{tabular}

Source: Campbell-Kelly 200I: I 25.

base (Farrell \& Saloner, 1986). Other events are Microsoft's bundling of DOS and Windows (Lee, 2000) and a pre-announcement strategy ('vaporware', see also Bayus et al., 2001), ${ }^{3}$ which puts competitors under pressure and signals to customers that new products are under way (Robertson et al., 1995). Microsoft's bundling strategy allowed the organization to abandon its cooperation with IBM and led to the exclusion of a relevant actor during the standard's formative phase. The standard's subsequent success and its high adoption rate eased pressures on Microsoft to include other actors during standard formation.

The failure of IBM's operating system OS/2 as well as the marginalization of alternative desktop operating systems was not only a consequence of Microsoft's installed base but also of its strategic approach: The year-long pre-announcement of Windows 95 illustrates the importance of expectations in market standardization processes: 'In a very real sense, the product that is expected to become the standard will become the standard' (Shapiro \& Varian, 1999, pp. 13-14; emphasis added). In the case of Windows, this self-fulfilling dynamic was further reinforced by an exponentially growing number of complementary Windows-specific applications, regularly tailored to local needs and provided by third-party software vendors, which further increased the attractiveness of the standard. This abundance of special purpose applications requiring Windows as an operating system standard has been identified as an 'applications barrier to entry' in a US antitrust case against Microsoft (Economides, 2001, p. 17) pointing to problematic distribution effects of Microsoft's global standard.

Once established, its ownership of the proprietary Windows standard allowed Microsoft to extend its market domination to more and more complementary fields, the most prominent one being the browser market (see Cusumano \& Yoffie, 1998). Microsoft's leeway for pricing and product politics remains substantial in spite of recent but still marginal competition from open source software alternatives such as Linux.

The successful and almost complete diffusion of Microsoft's products on desktop markets also led to remarkable shifts in the organization's competitive practices (see also Takahashi \& Namiki, 2003): Lacking serious competition in the marketplace, antitrust allegations in the US and the EU became the greatest threat to Microsoft's position as the dominant standard setter (see Ayres \& Nalebuff, 2005; Economides, 2001). Consequently, Microsoft started to engage more heavily in political lobbying: 'While Microsoft did not lobby prior to 1995, by 1998 it had a Washington office and spent US\$2.12m on lobbying using nine different contract lobbying firms. This might seem like a lot of activity, but by 2000, expenditures increased to US\$6.36m with 15 lobbying firms working for Microsoft' (Lowery, 2007, pp. 38-9). 
Interestingly, new market competition in the form of free/open source software such as Linux was politically motivated to some extent. The inventor of free software licensing and founder of the free software foundation, Richard Stallman (1999), claims that 'free software is a matter of free speech, not of free beer'. Contributors to and many users of free/open source software consider themselves part of a social movement (Dobusch \& Quack, 2010), which materializes in the form of software products turning actors into 'market rebels' (Rao, 2009). The salience of this renewed competition was demonstrated in 2009, when the open source web-browser Firefox overtook Microsoft's Internet Explorer in terms of European market share. This is remarkable, as Microsoft had stopped all development efforts in the sector after its victory in the famous 'browser war' (Cusumano \& Yoffie, 1998) and had to literally re-open its browser development department when Firefox started to gain a market share. In Microsoft's core market for desktop operating systems, however, challengers are less successful. Large municipalities such as Munich or Vienna faced severe difficulties in their attempts to switch their desktop software environments to free/open source software alternatives (Dobusch, 2008). As of 2011, only Munich continues with its migration project, while Vienna and other large adopters such as Berlin have delayed or even abandoned switching efforts.

From a standardization perspective, free/open source software development represents an allembracing, inclusive mode of standard formation (see Weber, 2004). Given that actors dispose of relevant technical knowledge as well as an understanding of the rules of the game, literally everybody from individual software developers such as Linus Torvalds, the founder of Linux, to large corporations such as IBM or Google is invited to contribute to free/open source software development. Some of these collaboratively developed standards are later formalized in the realm of committees such as the Linux Standard Base (LSB) hosted by the non-profit Linux Foundation. Another consequence of inclusive standard formation is a multitude of operating system distributions such as Debian, RedHat or Suse, which enhance competition.

Turning to the diffusion of free/open source software demonstrates the difficulties in challenging an established standard such as Microsoft Windows and Office, even when applying inclusive modes of standard formation. While the non-proprietary nature of free/open source software allows for competition and effectively prevents monopoly pricing, substantial switching costs significantly impede its proliferation (Dobusch, 2008; Shapiro \& Varian, 1999). So far, the high degree of diffusion and the network effects largely outweigh unfavourable distribution effects where they might exist at the individual and organizational levels. Microsoft's dominant position on the core markets of desktop operating and office systems has thus been largely unaffected by free/open source software competition (see Gosh et al., 2002; MERIT, 2006).

\subsection{From coexisting to collective rules: International Accounting Standards}

International Accounting Standards (IAS) or International Financial Reporting Standards (IFRS), as they have been called since 2001, have become accepted rules for the preparation of corporate financial accounts in more than 100 countries. Through acts of national law-making, IAS/IFRS have complemented or sometimes even replaced (pre-)existing national standards. These standards are developed by the International Accounting Standards Board (IASB), today a non-profit organization which has been active for more than 35 years. The IASB's organizational set-up has changed significantly over time, transforming the standard-setting body from a meta-organization comprised of national professional bodies into a not-for-profit foundation without institutional membership (details of the organization's development have been covered elsewhere, see Botzem, 2012; Botzem \& Quack, 2006, 2009; Camfferman \& Zeff, 2007; Martinez-Diaz, 2005; Perry \& 


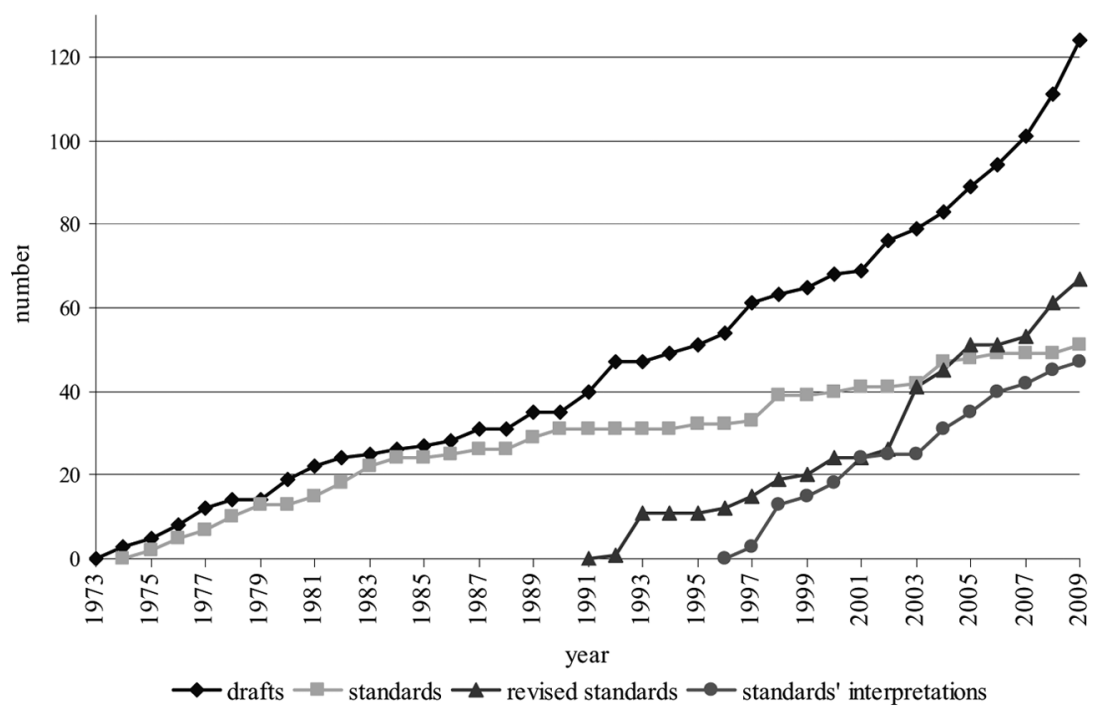

Figure 3. IASB's regulatory output 1973-2009 (cumulative) Source: Own composition.

Nölke, 2005; Tamm Hallström, 2004). Today, standards are developed by an expert body comprising 15 individuals who rely on a formalized due process as well as coordinated engagement with the business community and national and international regulators.

Throughout its history, the IASB's development has been contested. First, the organization had to compete with intergovernmental harmonization attempts made by the European Union and at the United Nations-level that were started in the late 1960s to bring about more uniform rules for the disclosure requirements of financial statements. In close cooperation with private and public actors from Anglo-American countries, the IASB managed to out-compete the rival initiatives and became the central actor developing global standards for financial reporting. However, the organization had to undergo severe organizational changes - in essence, imitating the formal structures of the US-American standards setter (Financial Accounting Standards Board, FASB). A second requirement was that international standards had to be put in line with the information requirements of capital market actors. Over time, the IASB's output grew at a steady rate. Standards were set, revised and interpreted by the IASB, later endorsed by public authority, and adopted by corporations. Figure 3 shows the development of the IASB's authoritative statements over time.

Over the years, IAS/IFRS have changed considerably and have become successively more capital market-oriented, establishing fair value accounting as a dominant paradigm. Originally, international standards were combinations of various national rules and therefore of a pluralist nature. Initially, they were merely redrafted and reformatted. This led to a vague catalogue of normative prescriptions which neither fulfilled national legal requirements nor satisfied the information needs of private actors such as banks, stock exchanges, analysts or institutional investors. At the end of the 1980s, the IASB began to review and revise all its standards, excluding most alternatives which were not in line with capital market-orientations. The revision of standards is still not entirely complete, but rival principals such as historical cost or replacement cost accounting have been marginalized. 
As mentioned above, the transformation of the IASB into an expert-oriented standard setter without democratic accountability came about after a number of actors agreed to back the IASB and its capital market-orientation. In the late 1990s substantial progress had been made with regard to the capital market-orientation of IAS, but official recognition by public authorities was still lacking. Most Anglo-American countries made the transformation of the IASB into an independent, private, not-for-profit organization a prerequisite to their decision to enforce international standards. By recognizing and implementing the rules, national law-makers positively affected diffusion and endowed both the organization itself and the standards it produces with output legitimacy. Consensus over the expert-centred formation of pro-capital market standards was a condition for later diffusion and subsequent enforcement at the national level. At the heart of this transformation was the reduction in the number of individuals deliberating in the decision-making body from over 50 to 14 . Since 2001 , the IASB has been dominated by standard-setting experts who rely on a refined due process fulfilling transparency requirements. Rather than being an instrument for participation, the due process is mostly a consultative exercise deployed by the organization's board (Botzem, 2012).

Today's IAS clearly adhere to the information needs of capital market actors. This makes them tools to further enhance the cross-border mobility of capital and therefore favoured their diffusion in an era of deregulating national financial markets. The EU's decision to make the IAS/IFRS mandatory from 2005 onwards certainly strengthened the IASB. However, diffusion of its standards also took other paths: one of the more subtle ways was the loan-granting policies of the World Bank, which requires states to adopt standards as national law. In some instances, private actors such as stock exchanges and private banks made standards obligatory through contractual agreements even in countries in which no legal provisions existed. Third parties, both private and public, play a significant role in making IAS/IFRS mandatory, often turning them into effectively binding rules. Among them are stock exchanges and banks that require IAS for their internal credit rating, but also international organizations such as the IMF, the World Bank or the International Organization of Securities Organizations, IOSCO (Tamm Hallström, 2004). The widespread diffusion of its standards strengthens the IASB and feeds back into the formation of standards: the IASB's dominant actors also interpret the acceptance of IAS/IFRS as an ex-post legitimation of the standards' formation.

The financial crisis has intensified criticism voiced earlier of both the normative content of IAS/ IFRS and the organizational set-up of the IASB. In particular the European Parliament, but also the interest representation of small- and medium-sized enterprises, have criticized a lack of accountability. Meanwhile, this has led to the inclusion of the new supervisory body in which regulatory agencies and international organizations are represented (Botzem, 2012). The EU and other jurisdictions use their power over the diffusion of IAS to influence the formation of standards at two levels: they call for a re-composition of the committees in which standard setting takes place and they voice demands concerning the normative content of standards. The IASB takes these challenges very seriously because it is well aware that criticism of its accountability and of the modes of standard formation potentially calls into question the legitimacy of its regulatory output.

\section{Comparing PC Operating Systems and International Accounting Standards}

\section{I Characteristics of standardization processes}

The main characteristics of our two examples can be summarized as follows: both cases show how an increase in the total number of adopters paves the way for - though does not guarantee - the 
dominance of a standard. Nevertheless, the ways of reaching a quasi-monopoly and further enhancing hegemony are distinct: in the case of operating systems, Windows emerged as the winner of a 'standard war' (Dranove \& Gandal, 2003) between different standard setters. This, however, was just a primary episode, followed by a proprietary monopoly standard that is developed exclusively by Microsoft, the standard's owner. The International Accounting Standards, by contrast, have taken a different road. They have been developed by private actors to rival existing national accounting requirements as well as emerging international regulations. Their diffusion only happened after lengthy negotiations between a coalition of public and private actors subsequently approving a reasonably coherent set of standards favouring capital market interest (cf. Botzem \& Hofmann, 2010). It was not until the late 1990s - after more than 25 years of organizational change and intense revision of standards - that the IASB managed to diffuse its standards globally. Table 4 summarizes and compares both cases.

Once a dominant standard is established, individual adopters not only enjoy coordination benefits but also encounter biases and constraints brought about by decisions taken previously. In the Windows case these are enforced product updates and monopoly pricing. In the case of the IAS, a focus on the information needs of capital market actors brings about a bias towards investor needs and distributional effects from labour to capital. Constraints on individual leeway as a result of previous decisions are one characteristic epitomizing the interrelatedness of standard formation and diffusion. Distributive effects resulting from widespread dissemination of rules feed back into the formation of standards and thus stabilize the standard-setting regime. In short, successful diffusion breeds - but does not guarantee - further success through increased output legitimacy. If the latter is considered to be high, it makes participation during standard formation a less pressing issue.

Similarly to multi-stakeholder approaches, the early IASB is an example of aiming for inclusive participation during the formation process in order to foster the later diffusion of rules. A high adoption rate signals that a chosen standard enjoys wide recognition and brings about output legitimacy, which affects standards formation in a positive way. Such a recursive relationship between output and input legitimacy can be observed in both cases. Formation and diffusion are two sides of the same coin of social ordering brought about by standards.

In addition, the comparison of Windows and IAS demonstrates that the logic of standard development can change substantially during the standardization process. The analytical distinction between formation and diffusion enables us to detect the underlying dynamics and to identify relevant actor groups. Over time, an established standard has the potential to reinforce power asymmetries between actor groups engaged in standardization processes. Despite differences in the formation of standards, Windows and IAS/IFRS have both emerged as leading rules in their field, sharing global distribution and becoming more similar with regard to a more exclusive mode of standard (re-)formation. Although to a varying degree, in both cases input legitimacy has been replaced in part by output legitimacy. Effective diffusion of rules contributes to a questioning of wide-ranging participation. In practice, this points to the relevance of issue-related expertise replacing democratic accountability.

\subsection{Different paths of standardization}

Our distinction between two dimensions of standardization accounts for the dynamic nature of standardization in general and the temporal ordering of successive steps in particular. In this section, we apply our two cases to the cyclical relationship of formation and diffusion and indicate the route they have been taking towards becoming global, quasi-obligatory rules. Figure 4 shows the development of our two examples along the dimensions mentioned above and characterizes the 
Table 4. Comparison of standardization processes

\begin{tabular}{|c|c|c|}
\hline & PC operating systems & Accounting standards \\
\hline $\begin{array}{l}\text { Standard } \\
\text { developer }\end{array}$ & Software publisher(s) & $\begin{array}{l}\text { International standard setting } \\
\text { body (IASB) }\end{array}$ \\
\hline Standard owner & Software publisher & $\begin{array}{l}\text { Copyright rests with a non-profit } \\
\text { foundation }\end{array}$ \\
\hline Standard selectors & Customers & Public and private authorities \\
\hline $\begin{array}{l}\text { Standard selection } \\
\text { mode }\end{array}$ & Market competition & Negotiation and argumentation \\
\hline $\begin{array}{l}\text { Logic of } \\
\text { standardization } \\
\text { process }\end{array}$ & Marginalization of alternatives & Synthesizing of alternatives \\
\hline $\begin{array}{l}\text { Coordination } \\
\text { benefits for } \\
\text { individual adopters }\end{array}$ & $\begin{array}{l}\text { - Interoperability and transferability of } \\
\text { know-how (direct network effects) } \\
\text { - Supply of complementary software, } \\
\text { service, personnel (indirect network } \\
\text { effects) }\end{array}$ & $\begin{array}{l}\text { - Cross-border comparability of } \\
\text { financial statements } \\
\text { - Facilitation of global allocation } \\
\text { of capital } \\
\text { - Fulfilling legal requirements } \\
\text { - Fulfilling requirements of third } \\
\text { parties (stock exchanges, banks) } \\
\text { who make standards binding } \\
\text { unilaterally }\end{array}$ \\
\hline $\begin{array}{l}\text { Standard bias/ } \\
\text { constraint for } \\
\text { individual adopters }\end{array}$ & $\begin{array}{l}\text { - Enforced product update cycles } \\
\text { - Monopoly pricing } \\
\text { - Switching costs (increasing over time) }\end{array}$ & $\begin{array}{l}\text { - Enforced capital market } \\
\text { orientation } \\
\text { - All information requirements } \\
\text { subordinated to investor needs } \\
\text { - Distribution effects from labour } \\
\text { to capital }\end{array}$ \\
\hline $\begin{array}{l}\text { Alternative } \\
\text { Standard }\end{array}$ & $\begin{array}{l}\text { Open source software ('Linux') } \\
\text { - Non-proprietary } \\
\text { - Participatory standard development and } \\
\text { selection } \\
\text { - Coordination deficits for individual } \\
\text { adopters }\end{array}$ & $\begin{array}{l}\text { Existing national accounting } \\
\text { standards }\end{array}$ \\
\hline
\end{tabular}

Source: Own composition.

way that they unfold over time. It indicates that there is not one best way to bring about social order at transnational levels, but that effective standardization rather depends on the contextual conditions and specific actor constellations. And while both standardization processes tracked in this study end up in the same quadrant, we warn against over-generalizing this result - not least because, from a cyclical perspective, any such 'end result' is likely to be only preliminary in nature.

While standardization in the field of desktop software markets was never very participative, the origins of the de-facto standard Windows clearly lie in the cooperation between Microsoft and the computer industry incumbent at the time, IBM. The legitimacy derived from expectations associated with IBM as a standard setter for computers is probably best illustrated by labelling PCs as ' $100 \%$ IBM compatible', which was still common at a time when actually compatibility with Microsoft Windows was crucial (see also Cottrell \& Koput, 1998). Later, Microsoft was only able to cut its ties with IBM after successfully disseminating DOS and Windows. The organization also 


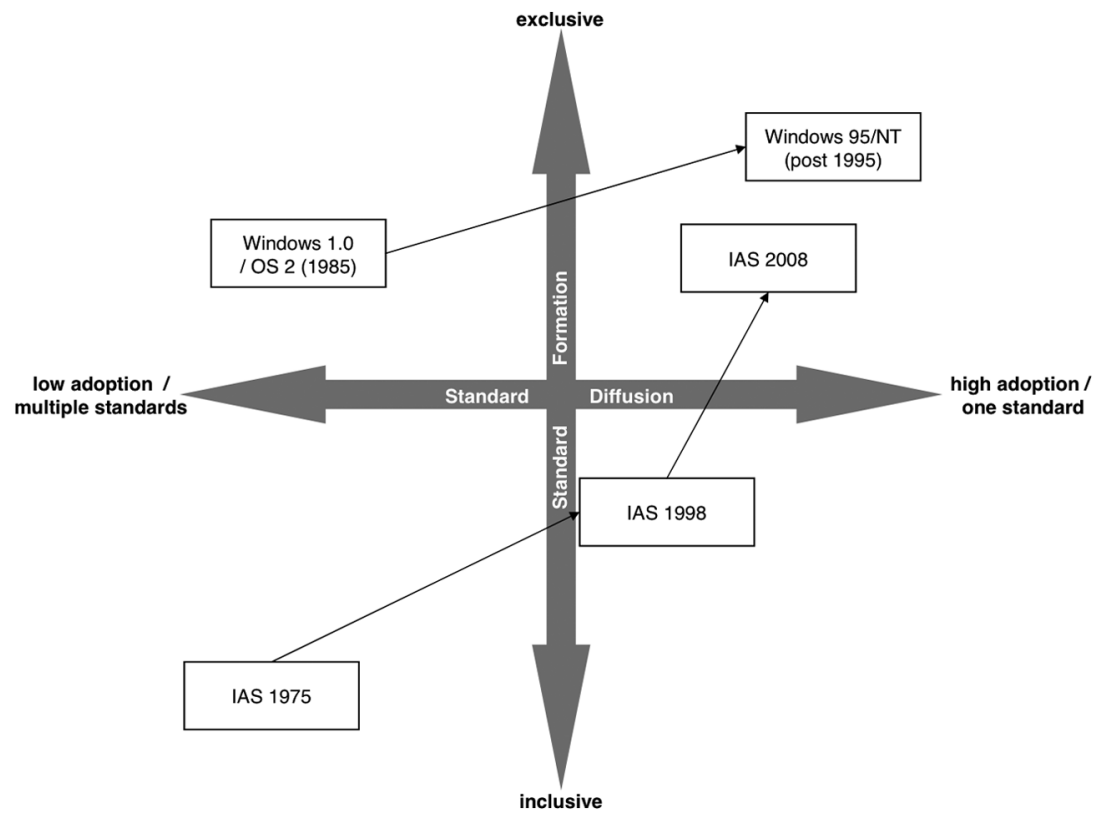

Figure 4. Dynamics of standard formation and diffusion over time

Source: Own composition.

managed to reap enormous profits from its position as a standard setter through both commercial (e.g. bundling strategies, Lee, 2000) and lobbying (Lowery, 2007) activities. Windows demonstrates how standard diffusion causes changes in the power distribution between standard adopters and standard developers - and how incumbents use their dominant position to conserve the monopoly they have managed to establish after out-competing rival standards. At the same time, however, increased spending on lobbying and the emergence of open source software indicate that output legitimacy alone doesn't ensure prevalence. Competitors and social movements challenge the market leader and its de-facto standard, making it necessary to compensate for insufficient input legitimacy.

By contrast, IAS's diffusion only happened after a lengthy process of bargaining and horsetrading. For many years, the IASB was not able to enjoy the benefits of its standards. While initially scoring high on input legitimacy, the inclusive process of standard formation stood in the way of providing an effective set of narrow enough standards. In this case, the imprecise rules hampered output legitimacy. It was not until a particular organizational structure of the IASB and an explicit capital market-orientation of its standards were chosen that diffusion of IAS/IFRS took place. Third parties emerged as particularly relevant in spurring the dissemination of standards after consensus over the core elements of the formation of standards had been reached. Now, after the formal adoption of IAS by public and private actors, the IASB's standards and with them the entire transnational standardization network appear to be largely unchallenged, in particular because they have been made legally binding in many jurisdictions. As a whole, transnational accounting standardization is less participatory than in the beginning, one reason being the clearcut financial market orientation. This is taken for granted in order to engage discussions and procedures of standard setting. In terms of both the modes of standardization and the configuration of 
the rules, a commitment to capital market logics is the eye of the needle and expertise-based discourse creates a high entry barrier, particularly for civil society. Even the financial crisis does not seem to have led to serious reconfigurations of the IASB or its normative output.

\section{Discussion: Recursiveness in Standardization}

Our process perspective reveals two core insights of transnational standardization cycles in desktop software and accounting: the mutual relation of different types of legitimacy and the distributive effects inherent in cycles of transnational standardization.

First, in the formative phases of standardization, the participation of various actors fosters standards' legitimacy, acceptance and adoption. However, an inclusive mode of standard formation complicates the drafting of clear-cut rules. Nevertheless, procedural characteristics of standard development and the specific organizational context are vital for standardization at the transnational level. Input legitimacy stemming from participation becomes a powerful source of authority for private cross-border standardization but is not sufficient for lasting success. High adoption rates are equally important for long-term survival. This makes output legitimacy the other key element in bringing about stable social order through standards.

Empirically, we have shown that increasing diffusion of standards contributes to replacing input with output legitimacy. In the case of the IASB, the number of representatives was reduced and an elaborate consultation procedure was introduced as standards became more widely diffused. Microsoft, in turn, was no longer dependent on its cooperative partnership with IBM once it had secured market dominance. Until today, the software corporation has still been able to fend off competition from alternative free/open source software standards such as Linux, which rely on very inclusive modes of standard setting. The Windows example also illustrates how compatibility and high switching costs provide output legitimacy for both standard adopters and the standard itself: while not necessarily liked by all adopters, the continuous re-adoption of Windows is considered normal by the vast majority of followers, which in turn strengthens the output legitimacy of the standard. In both cases output legitimacy has partially superseded input legitimacy, but the reaction of outsiders varies. While demands for inclusion to formulate proprietary desktop standards are largely insignificant, the IASB is facing substantial criticism. Private standard-setting organizations claiming to act in the public interest are confronted by more demanding requests for input legitimacy.

In line with previous works (Quack, 2010; Tamm Hallström \& Boström, 2010), distinguishing between different types of legitimacy provides a fruitful way of understanding the interrelatedness of standard setting and standard dissemination. The submission of diverse actors contributes to the obligatory nature of privately set standards. Network effects and diffusion are potent mechanisms providing standards with considerable momentum to become quasi binding modes of government beyond the state (Rose \& Miller, 1992). In fact, standards' acceptance and enforcement by private and public third parties can be considered a prerequisite before turning standards into de-facto prescriptive rules (Brunsson \& Jacobsson, 2000c; Kerwer, 2005; Tamm Hallström, 2004). This is also true in our cases, success stories of transnational rule-making in this respect. Despite different degrees of participation and binding quality, they are distinct from other, less successful cases: until now, they have managed to somehow balance input and output legitimacy or have at least managed to argue convincingly that they adequately account for the need to balance the two (Tamm Hallström \& Boström, 2010). Taking this finding further, future research is needed to map out in more detail how different forms of legitimacy are related to each other by the actors involved. This allows for further specification of the characteristics of recursive standardization cycles. 
In this context, future work may also explore the standardization of standardization procedures, something that could be called second-order standardization. This would be in line with our cyclical view of standardization, where standards are far from being 'irreversible' (Borraz, 2007, p. 62). They are subject to continuous adaptation and re-formulation. In this regard, the rationale of modern organizations, such as transparency and effectiveness (cf. Quack, 2010), provides an additional source of legitimacy feeding into the standardization cycle.

Second, high adoption rates contribute to the (re)distribution of benefits, favouring already privileged actors. They feed back into the standard formation processes, allowing them to exercise influence and dominate less influential interest groups (see Mattli \& Büthe, 2005). Powerful actors with privileged access to standard development are in a good position to secure their dominance, further benefitting from the characterized shift from input to output legitimacy. Sometimes, as in desktop software, one formal organization dominates the entire process. In financial reporting, a transnational network of organizations dominates standardization and distributes the benefits amongst its members. In both cases, organizational guidelines, such as codified rule-setting procedures, are not only a core element of standardization, they also evolve over time. However, excessive influence of focal actors, such as Microsoft, may provoke oppositional movements, as can be seen in the free/open source software movement in the Windows case (see Dobusch \& Quack, 2010; Stallman, 1999).

As a result, participation should not only be seen as an abstract normative requirement but must be taken into consideration throughout the entire standardization process with regard to its empirical consequences (see Cutler, 2010). If mastered convincingly, private standard setters fill the transnational regulatory void - but only in conjunction with other actors needed to (re-)contextualize standards according to local requirements. In the Windows case, these adaptations happen largely in the form of complementary application software provided by third-party vendors, which are responsive to local peculiarities but also contribute to the application barrier to entry for potential competitors. Thus, advocates of free/open source software alternatives have to convince both adopters and third-party software vendors to support an alternative standard in order to challenge Microsoft's global dominance. In accounting, the local contextualization of rules is similarly critical to ensure the transformation of abstract rules into practice. Extending our process model of standardization to include different levels of standard setting and adoption would be another worthwhile avenue for further research.

More generally, our case analysis confirms that the importance of the distributive effects of standardization is a constitutive element of any standard. A process perspective can adequately account for the (re-)distribution of benefits, an insight often missed by functional approaches to standard setting, which argue merely in favour of reduced transaction costs (e.g. Abbott \& Snidal, 2001; Liebowitz \& Margolis, 2001). It also supports more normative accounts that demand democratically acceptable procedures, particularly as the recursiveness of standardization indicates a reinforcement of these dynamics over time. Such feedback loops point to the important role of public actors even in private standardization. Their activities drive or hinder diffusion, which makes them core players in the field. This feedback loop is evidenced by the EU Commission's role in making IAS mandatory, thereby further driving their diffusion. It also becomes clear in US and EU antitrust trials against Microsoft, striving to curtail the latter's monopoly power derived from its Windows standard.

As is also evidenced by our cases, the partial replacement of input legitimacy by output legitimacy is unlikely to be something like the 'final stage' of a linear standardization process, as implied by Timmermans and Epstein (2010). Instead, it might inspire renewed demands for - probably new forms of - input legitimacy. In the Windows case these demands are at the heart of politically 
motivated campaigns for the adoption of open source software. In accounting, demands for more participation are fuelled by criticism of its narrow financial market orientation, most evident at the height of the financial crisis. The relationship and interaction between input and output legitimacy in standardization processes is recursive and potentially endless.

\section{Conclusion}

We conclude the paper by summing up our findings: First, analytically differentiating between standard formation and diffusion and integrating both elements in a process-oriented framework of standardization allows us to overcome the blind spots of functional and social approaches. Second, the same distinction between formation and diffusion provides four ideal types of standards which enable us to track the transformation of standards over time. Third, our examples show that the ways of 'organizing standardization' are subject to change. Core organizational aspects of standardization are the procedures of standard setting and the configurations of standard-setting organizations themselves. Fourth, stakeholder engagement is crucial in transnational standardization processes as the main source of input legitimacy. Fifth, feedback between output legitimacy and standard diffusion constitutes an additional feedback loop within the overall recursive cycle of standardization.

In a nutshell, the additional value of our cyclical process model of transnational standardization consists in conceptualizing the mutual dependence of standards' formation and their subsequent diffusion. Long-lasting developments can only be understood adequately when fully grasping how the different sequences of transnational standardization relate to each other. Such a dynamic perspective is needed not only to understand change and institution-building at the transnational level. It also helps to integrate conceptual approaches emphasizing the political nature of standardization with functional perspectives strengthening the coordinative aspects of standards. Gains in output legitimacy may not necessarily result in the overall and long-term stability of a standard, specifically when these gains result from or lead to decreased input legitimacy. In addition to the avenues for further research sketched above, we would therefore see benefits in re-assessing already researched cases of prominent standards, for example some ISO standards, through such a lens of cyclical standardization. Most importantly, accounting for such recursive dynamics allows for a more concise characterization of social order beyond the nation-state: its dynamics unveil the inherent instability and the necessity to make standards resonate with adopters and the public as a whole.

\section{Acknowledgements}

We would like to thank all participants of Sub-theme 13, 'The social dynamics of standardization', of the 2009 EGOS colloquium in Barcelona and in particular Nils Brunsson, Andreas Rasche, and David Seidl for providing many valuable comments as guest editors of this issue. We are also grateful to three anonymous reviewers for many insightful questions and remarks. In addition, we would like to thank Sigrid Quack and Arndt Sorge for many helpful suggestions along the way.

\section{Notes}

1. Recent discussions of the role of legitimacy in transnational rule-making point to the importance of transparency (Tamm Hallström \& Boström, 2010, pp. 149ff.), and procedural fairness and impartiality (Quack, 2010, pp. 7ff.). We acknowledge the importance of procedural legitimacy, particularly in multistakeholder arrangements, and support the idea of treating it as a stand-alone category, especially when doing empirical research. However, in order to address general issues of standardization and to keep our 
model of recursive cycles in transnational standardization simple, in this article we have opted to subsume procedural legitimacy under input legitimacy.

2. DIN Standards are the authoritative statements of Germany's national standardization organization (Deutsches Institut für Normung e.V.; German Institute for Standardization). Currently there are about 30,000 DIN standards. One of the best-known ones is standard DIN 476, which introduced the A-series paper sizes in 1922. In 1975 it was adopted as international standard ISO 216. Notable exceptions of paper formats exist primarily in North America.

3. In their definition of VaporWare, Dranove and Gandal (2000, p. 1) even cite Microsoft's Press Computer Dictionary: 'Strategic product preannouncements are often referred to as vaporware. According to the 1991 Microsoft Press Computer Dictionary, vaporware is defined as "promised software that misses its announced release date, usually by a considerable length of time." Thus vaporware includes products arriving significantly late due to unexpected technical difficulties and products that arrive late because of strategic preannouncements.'

\section{References}

Abbott, Kenneth W., \& Snidal, Duncan (2001). International 'standards' and international governance. Journal of European Public Policy, 8, 345-370.

Ahrne, Göran, \& Brunsson, Nils (2006). Organizing the world. In M.-L. Djelic \& K. Sahlin-Andersson, (Eds.), Transnational governance: Institutional dynamics of regulation (pp. 74-94). Cambridge: Cambridge University Press.

Ahrne, Göran, Brunsson, Nils, \& Tamm Hallström, Kristina (2007). Organizing organizations. Organization, 14, 619-624.

Arthur, Brian W. (1989). Competing technologies, increasing returns, and lock-in by historical events. The Economic Journal, 99, 116-131.

Arts, Bas (2003). Non-state actors in global governance: Three faces of power. Preprint, Max-PlanckProjektgruppe, Recht der Gemeinschaftsgüter. Bonn: Max-Planck-Gesellschaft.

Ayres, Ian, \& Nalebuff, Barry (2005). Going soft on Microsoft? The EU's antitrust case and remedy. The Economist's Voice, 2, Article 4.

Bartley, Tim (2007). Institutional emergence in an era of globalization: The rise of transnational private regulation of labor and environmental conditions. American Journal of Sociology, 113, 297-351.

Bayus, Barry L., Jain, Sanjay, \& Rao, Ambar G. (2001). Truth or consequences: An analysis of vaporware and new product announcements. Journal of Marketing Research, 38, 3-13.

Becker, Eberhard, Buhse, Willms, Günnewig, Dirk, \& Rump, Niels (Eds.) (2003). Digital rights management: Technological, economic, legal and political aspects. Berlin: Springer.

Besen, Stanley M., \& Farrell, Joseph (1994). Choosing how to compete: Strategies and tactics in standardization. Journal of Economic Perspectives, 8, 117-131.

Boli, John, \& Thomas, George M. (1999). Constructing world culture. International nongovernmental organizations since 1875. Stanford, CA: Stanford University Press.

Borraz, Olivier (2007). Governing standards: The rise of standardization processes in France and in the EU. Governance, 20, 57-84.

Botzem, Sebastian (2012). The politics of accounting regulation: Organizing transnational standard setting in financial reporting. Cheltenham: Edward Elgar.

Botzem, Sebastian, \& Hofmann, Jeanette (2010). Transnational governance spirals: The transformation of rule-making authority in internet regulation and corporate financial reporting. Critical Policy Studies, 4 , $18-37$.

Botzem, Sebastian, \& Quack, Sigrid (2006). Contested rules and shifting boundaries: International standard setting in accounting. In M.-L. Djelic \& K. Sahlin-Andersson (Eds.), Transnational governance: Institutional dynamics of regulation. (pp. 266-286). Cambridge: Cambridge University Press.

Botzem, Sebastian, \& Quack, Sigrid (2009). (No) limits to Anglo-American accounting? Reconstructing the history of the International Accounting Standards Committee: A review article. Accounting, Organizations and Society, 34, 988-998. 
Braithwaite, John, \& Drahos, Peter (2000). Global business regulation. Cambridge: Cambridge University Press.

Brunsson, Nils, \& Jacobsson, Bengt (Eds.) (2000a). A world of standards. Oxford: Oxford University Press. Brunsson, Nils, \& Jacobsson, Bengt (2000b). The contemporary expansion of standardization. In Brunsson, N., \& Jacobsson, B. (Eds.), A world of standards (pp.1-17). Oxford: Oxford University Press.

Brunsson, Nils, \& Jacobsson, Bengt (2000c). Following standards. In N. Brunsson \& B. Jacobsson (Eds.), $A$ world of standards (pp. 125-137). Oxford: Oxford University Press.

Camfferman, Kees, \& Zeff, Stephen A. (2007). Financial reporting and global capital markets: A history of the International Accounting Standards Committee 1973-2000. Oxford: Oxford University Press.

Campbell-Kelly, Martin (2001). Not only Microsoft: The maturing of the personal computer software industry, 1982-1995. Business History Review, 75, 103-145.

Campbell-Kelly, Martin (2003). From airline reservations to sonic the hedgehog: A history of the software industry. Cambridge, MA: MIT Press.

Cargill, Carl F. (1989). Information technology standardization: Theory, process, and organizations. Maynard, MA: Digital Press.

Cottrell, Tom, \& Koput, Ken (1998). Software variety and hardware value: A case study of complementary network externalities in the microcomputer software industry. Journal of Engineering and Technology Management, 15, 309-338.

Cusumano, Michael A., Mylonadis, Yiorgos, \& Rosenbloom, Richard S. (1992). Strategic maneuvering and mass-market dynamics: The triumph of VHS over Beta. Business History Review, 66, 51-94.

Cusumano, Michael A., \& Yoffie, David B. (1998). Competing on internet time: Lessons from Netscape and its battle with Microsoft. New York: The Free Press.

Cutler, A. Claire (2010). The legitimacy of private transnational governance: Experts and the transnational market for force. Socio-Economic Review, 8, 157-185.

Cutler, A. Claire, Haufler, Virginia, \& Porter, Tony (1999). Private authority and international affairs. Albany, NY: State University of New York Press.

David, Paul A. (1985). Clio and the economics of QWERTY. American Economic Review, 75, 332-337.

David, Paul A., \& Greenstein, Shane (1990). The economics of compatibility standards: An introduction to recent research. Economics of Innovation and New Technologies, 1, 3-41.

Delmas, Magali A. (2002). The diffusion of environmental management standards in Europe and in the United States: An institutional perspective. Policy Sciences, 35, 91-119.

Djelic, Marie-Laure, \& Quack, Sigrid (2003). Globalization and institutions. Redefining the rules of the economic game. Cheltenham: Edward Elgar.

Djelic, Marie-Laure, \& Sahlin-Andersson, Kerstin (2006). Institutional dynamics in a re-ordering world. In M.-L. Djelic \& K. Sahlin-Andersson (Eds.), Transnational governance: Institutional dynamics of regulation (pp. 375-397). Cambridge: Cambridge University Press.

Dobusch, Leonhard (2008). Windows versus Linux: Markt - Organisation - Pfad. Wiesbaden: VS Verlag für Sozialwissenschaften.

Dobusch, Leonhard, \& Quack, Sigrid (2010). Epistemic communities and social movements: Transnational dynamics in the case of creative commons. In M.-L. Djelic \& S. Quack (Eds.), Transnational communities: Shaping global economic governance (pp. 226-251). Cambridge: Cambridge University Press.

Dranove, David, \& Gandal, Neil (2000). The DVD vs. DIVX standard war: Empirical evidence of vaporware. U.C. Berkeley Competition Policy Center Working Paper.

Dranove, David, \& Gandal, Neil (2003). The DVD-vs.-DIVX standard war: Empirical evidence of network effects and preannouncement effects. Journal of Economics \& Management Strategy, 12, 363-386.

Economides, Nicholas (2001). The Microsoft antitrust case. Journal of Industry, Competition and Trade, 1, 7-39.

Egyedi, Tineke (1996). Shaping standardization: A study of standards processes and standards policies in the field of telematic services. Delft: Delft University Press.

Farrell, Joseph, \& Saloner, Garth (1986). Installed base and compatibility: Innovation, product preannouncements, and predation. The American Economic Review, 76, 940-955. 
Farrell, Joseph, \& Saloner, Garth (1987). Competition, compatibility and standards: The economics of horses, penguins and lemmings. In H. Landis Gabel (Ed.), Product standardization and competitive strategy (pp. 1-21). Amsterdam: North-Holland.

Feng, Patrick (2003). Studying standardization: Review of the literature. Proceedings of the 3rd IEEE Conference on Standardization and Innovation, 22-24 October, Delft, The Netherlands.

Fransen, Luc W., \& Kolk, Ans (2007). Global rule-setting for business: A critical analysis of multistakeholder standards. Organization, 14, 667-684.

Funk, Jeffrey L., \& Methe, David T. (2001). Market- and committee-based mechanisms in the creation and diffusion of global industry standards: The case of mobile communication. Research Policy, 30, 589-610.

Garud, Raghu, \& Karnøe, Peter (2003). Bricolage vs. breakthrough: Distributed and embedded agency in technology entrepreneurship. Research Policy, 32, 277-300.

Genschel, Philip (1997). How fragmentation can improve co-ordination: Setting standards in international telecommunications. Organization Studies, 18, 603-622.

Gosh, Rishab Aiyer, Krieger, Bernhard, Glott, Ruediger, \& Robles, Gregorio (2002). Free/libre and open source software: Survey and study. Part 2B: Open source software in the public sector: Policy within the European Union. International Institute of Infonomics, University of Maastricht. Retrieved from: http:// www.flossproject.org/report/FLOSSFinal_2b.pdf

Halliday, Terence C., \& Carruthers, Bruce G. (2007). The recursivity of law: Global norm making and national lawmaking in the globalization of corporate insolvency regimes. American Journal of Sociology, $112,1135-1202$.

Hemenway, D. (1975). Industry wide voluntary product standards. Cambridge, MA: Ballinger.

Katz, Michael L., \& Shapiro, Carl (1985). Network externalities, competition and compatibility. American Economic Review, 75, 424-440.

Keil, Thomas (2002). De-facto standardization through alliances: Lessons from Bluetooth. Telecommunications Policy, 26, 205-213.

Kerwer, Dieter (2005). Rules that many use: Standards and global regulation. Governance, 18, 611-632.

Koski, Heli, \& Kretschmer, Tobias (2005). Entry, standards and competition: Firm strategies and the diffusion of mobile telephony. Review of Industrial Organization, 26, 89-113.

Lampland, Martha, \& Star, Susan L. (Eds.) (2009). Standards and their stories: How quantifying, classifying, and formalizing practices shape everyday life. Ithaca: Cornell University Press.

Layder, Derek (1998). Sociological practice: Linking theory and social research. London: Sage.

Lee, Sang-yong T. (2000). Bundling strategy in base-supplemental goods markets: The case of Microsoft. European Journal of Information Systems, 9, 217-225.

Liebowitz, Stan J., \& Margolis, Stephan E. (2001). Winners, losers \& Microsoft: Competition and antitrust in high technology - Revised edition. Oakland: The Independent Institute.

Lövbrand, Eva, Rindefjäll, Teresia, \& Nordqvist, Joakim (2009). Closing the legitimacy gap in global environmental governance? Lessons from the emerging CDM market. Global Environmental Politics, 9, 74-100.

Lowery, David (2007). Why do organized interests lobby? A multi-global, multi-context theory of lobbying. Polity, 39, 29-54.

Martinez-Diaz, Leonardo (2005). Strategic experts and improvising regulators: Explaining the IASB's rise to global influence, 1973-2001. Business and Politics, 7, Art. 3.

Mattli, Walter (2003). Public and private governance in setting international standards. In M. Kahler, \& D. Lake (Eds.), Governance in a global economy: Political authority in transition (pp. 199-225). Princeton: Princeton University Press.

Mattli, Walter, \& Büthe, Tim (2005). Accountability in accounting? The politics of private rule-making in the public interest. Governance, 18, 399-429.

Mayntz, Renate (2010). Legitimacy and compliance in transnational governance. Working Paper 10/5. Cologne: Max Planck Institute for the Study of Societies. 
MERIT (Ed.) (2006). Study on the economic impact of open source software on innovation and the competitiveness of the information and communication technologies (ICT) sector in the EU - Final report. Retrieved from http://ec.europa.eu/enterprise/ict/policy/doc/2006-11-20-flossimpact.pdf.

North, Douglass C. (1990). Institutions, institutional change and economic performance. Cambridge: Cambridge University Press.

Pattberg, Philipp (2005). The institutionalization of private governance: How business and nonprofit organizations agree on transnational rules. Governance, 18, 589-610.

Perry, James, \& Nölke, Andreas (2005). International accounting standard setting: A network approach. Business and Politics, 7, Art. 5.

Pettigrew, Andrew M. (1990). Longitudinal field research on change: Theory and practice. Organization Science, 1, 267-292.

Quack, Sigrid (2007). Legal professionals and transnational law-making: A case of distributed agency. Organization, 14, 643-666.

Quack, Sigrid (2010). Law, expertise and legitimacy in transnational economic governance: An introduction. Socio-Economic Review, 8, 3-16.

Rao, Hayagreeva (2009). Market rebels: How activists make or break radical innovations. Princeton: Princeton University Press.

Robertson, Thomas S., Eliashberg, Jehoshua, \& Talia, Rymon (1995). New product announcement signals and incumbent reactions. Journal of Marketing, 59, 1-15.

Rose, Nikolas, \& Miller, Peter (1992). Political power beyond the state: Problematics of government. British Journal of Sociology, 43, 173-205.

Rosenblatt, Bill, Trippe, Bill, \& Mooney, Stephen (2002). Digital rights management: Business and technology. New York: M\&T Books.

Scharpf, Fritz W. (1999). Governing in Europe. Effective and democratic? Oxford: Oxford University Press.

Schmidt, Susanne K., \& Werle, Raymund (1993). Technical controversy in international standardization. Discussion Paper 93/5. Cologne: Max Planck Institute for the Study of Societies.

Schmidt, Susanne K., \& Werle, Raymund (1998). Coordinating technology: Studies in the international standardization of telecommunications. Cambridge, MA: MIT Press.

Seidl, David (2007). Standard setting and following in corporate governance: An observation. Theoretical study of the effectiveness of governance codes. Organization, 14, 705-727.

Shapiro, Carl, \& Varian, Hal R. (1999). Information rules: A strategic guide to the network economy. Boston, MA: Harvard Business School Press.

Stallman, Richard (1999). The GNU operating system and the free software movement. In C. DiBona, S. Ockman, \& M. Stone (Eds.), Open sources: Voices from the open source revolution (pp. 53-70). Sebastopol, CA: O'Reilly.

Storz, Cornelia (2007). Compliance with international standards: The EDIFACT and ISO 9000 standards in Japan. Social Science Japan Journal, 10, 217-241.

Suchman, Marc C. (1995). Managing legitimacy: Strategic and institutional approaches. The Academy of Management Review, 20(3), 571-610.

Takahashi, Takuma, \& Namiki, Fujio (2003). Three attempts at 'de-Wintelization': Japan's TRON project, the US government's suits against Wintel, and the entry of Java and Linux. Research Policy, 32, 1589-1606.

Tamm Hallström, Kristina (2004). Organizing international standardization. ISO and the IASC in quest of authority. Cheltenham: Edward Elgar.

Tamm Hallström, Kristina, \& Boström, Magnus (2010). Transnational multi-stakeholder standardization organizing fragile non-state authority. Cheltenham: Edward Elgar.

Timmermans, Stefan, \& Epstein, Steven (2010). A world of standards but not a standard world: Toward a sociology of standards and standardization. Annual Review of Sociology, 36, 69-89.

Weber, Steven (2004). The success of open source. Cambridge, MA: Harvard University Press.

Weitzel, Tim, Beimborn, Daniel, \& König, Wolfgang (2006). A unified economic model of standard diffusion: The impact of standardization cost, network effects, and network topology. MIS Quarterly, 30, 489-514. 
Werle, Raymund, \& Iversen, Eric J. (2006). Promoting legitimacy in technical standardization. Science, Technology \& Innovation Studies, 2, 19-39.

Willke, Helmut (2007). Smart governance: Governing the global knowledge society. Frankfurt/M.: Campus.

\section{Author biographies}

Sebastian Botzem is research fellow at the Social Science Research Center in Berlin. He earned his PhD from the Freie Universität Berlin. His research interests include transnational regulation, multi-level governance and organizations in international political economy. He recently published The Politics of Accounting Regulation: Organizing Transnational Standard Setting in Financial Reporting (Edward Elgar 2012).

Leonhard Dobusch is research fellow at the Department of Management at Freie Universität Berlin, where he also earned his $\mathrm{PhD}$. His research interests include transnational standardization, governance of digital communities and information technology adoption. Among his recent publications is 'Serial Singularities: Developing a Network Organization by Organizing Events' in Schmalenbach Business Review (together with Gordon Müller-Seitz). 